\title{
Mine closure residual risk management: identifying and managing credible failure modes for tailings and mine waste
}

\author{
J Sanders Klohn Crippen Berger Ltd., Canada \\ H McLeod Klohn Crippen Berger Ltd., Canada \\ A Small Klohn Crippen Berger Ltd., Canada \\ C Strachotta Klohn Crippen Berger Ltd, Australia
}

\begin{abstract}
Closure planning relies on a solid understanding of risk management. With tailings and other mine waste facilities representing a significant life-of-mine (LoM) liability associated with the mining industry, a proper understanding and management of residual risk at closure is fundamental to implementing a mine closure plan that will be considered successful. Having a comprehensive technical basis of the triggering events and credible failure modes after closure that may impact receptors and prohibit meeting closure objectives is crucial. Performance evaluation and success criteria can then be properly developed and assessed against closure objectives and obligations.

In the wake of the recent Mount Polley, Fundão and Brumadinho mine tailings disasters, we are reminded that decisions made, past and present, affect the social acceptability of the industry in the future. The physical stability mechanisms that caused these tailings dam failures to occur can be present throughout the LoM into post-closure and represent an unacceptable long-term risk to society and the mine owner. Existing and closed facilities will still require post-closure stewardship to ensure protection of life, property and the environment regardless of future improved tailings technologies for new projects.

Risk assessment can be a valuable tool for providing insight to the safety of a tailings facility and educating the mine closure planning team. Risk assessments should be conducted at each phase of a mine life, from design to closure, and are often undertaken. However, the authors of this paper have identified several challenges with risk assessments and, in this paper, have provided several recommendations to improve risk assessments for dam safety. We have built upon the guidance provided by ISO 3100:2018 on risk management. With this foundation established, the paper then discusses some of the unique challenges and relevant case studies associated with risk assessments for closure residual risk. If the risk assessments conducted during design and operation are flawed, then the risk assessment for the closure residual risk will have reduced value.
\end{abstract}

Keywords: mine closure, post-closure residual risk, credible failure modes, tailings and mine waste

\section{Introduction}

Tailings and mine waste facilities represent the most significant reputational, financial, environmental and social liability associated with the mining industry. A comprehensive understanding and management of potentially credible failure modes after mine operations cease is fundamental to the success of implementing a mine closure plan. Such an understanding will assist with developing realistic life of mine (LoM) and post-closure cost ranges and accurately communicate post-closure risk with key stakeholders.

Before undertaking a risk assessment for post-closure, risk assessments should be done during the initiation design and operational phases of a LoM. The results of these risk assessments can be extended to the closure risk assessment. However, it is important that the risk assessments that are done before closure are 
comprehensive, effective, and able to be updated over the LoM. Hence, this paper begins with a discussion on suggested improvements to typical dam safety risk assessment methods.

The paper then continues with a discussion on post-closure residual risk and considerations for risk assessment. The paper concludes with a summary of the value of front-end loading (FEL) practices, of how to apply risk assessment into FEL practices, and of case studies from closed tailings sites that have demonstrate a lower dam safety residual risk.

\section{$2 \quad$ Improvements to tailings safety risk assessment}

The Ernst and Young top 10 business risks facing mining and metals in 2019-2020 report highlights 'license to operate' as the number one business risk facing mining companies (Ernst and Young 2019). In the wake of the recent Mount Polley, Fundão and Brumadinho mine tailings disasters, we are reminded that decisions made, past and present, affect the social acceptability of the industry in the future.

The mechanisms that caused these tailings dam failures to occur can be present throughout the LoM into post-closure and represent an unacceptable long-term risk to society. Existing and closed facilities will still require post-closure stewardship to ensure protection of life, property and the environment regardless of future improved tailings technologies for new projects.

There are several different risk assessment methods and many of them are done well. However, the experience of the authors indicates that there is room for improvement in dam safety risk assessment that can support closure residual risk assessment. This section summarises the authors experiences in observed areas of improvement for assessment of post-closure residual risk. As a basis, we refer to the risk management guideline provided in ISO 31000:2018 (International Organization for Standardization 2018). Figure 1 shows the key processes outlined in ISO 31000:2018.

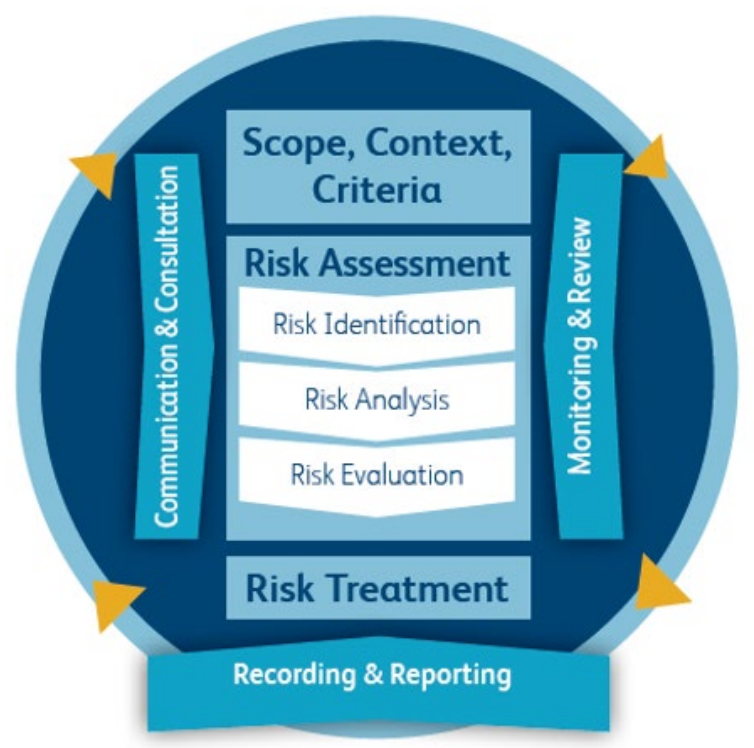

Figure 1 Risk management key processes (from International Organization for Standardization 2018)

Table $A$ at the end of this paper provides a description of steps in ISO 3100:2018 process, the pitfalls that the authors have observed and suggestions for improvement for dam safety risk assessment. Some of the key suggestions includes:

- The risk scenario being assessed should be well defined (e.g. current operations, upset conditions, closure transition, active care, passive care, etc.). This can be a challenge with respect to post-closure residual risk assessment when the closure plans are at a conceptual or high level and is discussed below.

- Having a comprehensive technical basis of the triggering events and credible failure modes for tailings and mine waste structures is crucial. Preparing event trees with a team of technically 
qualified and experienced people is beneficial in supporting the identification of credible and on-credible failure modes.

- Non-credible failure modes should not be carried forward in the risk assessment. They should be included in the risk register with an explanation as to why they are not credible. By doing so, these failure modes can be considered in subsequent risk assessments and the conclusions about credibility re-assessed. Dam safety and closure surveillance programs should reflect this.

- The typical operational risk definitions of likelihood do not handle well natural events (e.g. flood or earthquake) that are typical from a dam safety or long-term mine closure perspective. We have developed an alternative approach that has proven to be useful in better elucidating the risks and supporting identification of critical controls.

- Risk treatments would benefit from a program with quantitative performance metrics to demonstrate success against clear measurable closure objectives. Improved engagement and forward planning can then be established with closure stakeholders.

- Many of the tailings failures are a culmination of smaller but related events that typically has a human element at the centre. Human factors including normalisation of deviance has to be accounted for in the risk assessment process through governance assurance measures (e.g. internal and independent dam safety evaluations, independent tailings review boards, and closure working groups involving external stakeholders).

- In the wake of recent catastrophic tailings dam failures, Morgenstern's de Mello (2018) calls for a culture shift in tailings management towards a performance-based, risk-informed safe design, construction, operation, and closure (PBRISD) approach (Morgenstern 2018). However, the concept of a 'risk-informed safe design' is a challenge to communicate with external stakeholders as there remains no independent and objective means of quantifying consequences and determining what is socially acceptable.

- Risk communication is an opportunity for improvement. The results and nature of credible failure mode(s) assumed must be explainable to the least technical person that will be in a target audience. There remain challenges in objectively quantifying the likelihood and consequence of credible failure modes for external stakeholders in determining what is socially acceptable residual risk. A case by case approach with early engagement is recommended to define risk terms and identify the range of tolerable and intolerable post-closure risk.

The following sections focus on application of the risk assessment process to post-closure residual risk.

\section{Post-closure residual risk}

\subsection{What is post-closure residual risk?}

The ISO3100:2018 risk management guide defines risk as 'the effect of uncertainty on objectives' and residual risk as the 'risk left over after implementing a risk treatment option' (International Organization for Standardization 2018). The 2019 International Council on Mining and Metals (ICMM) integrated mine closure guide defines residual risk as 'the remaining risk after management actions have been implemented to reduce the initial risk' (ICMM 2019).

Post-closure residual risk can therefore be described as the remaining risk in not achieving closure objectives, considering that preventative and mitigative reclamation measures are implemented and effective. Mine closure risk treatments that support a closure plan can vary from elimination of the source of the hazard, modifying the consequences, changing the likelihood, transferring the risk, or accepting the risk. The application of risk management techniques and financial assurance calculations should reflect the range of uncertainty and resiliency to these risk treatment approaches. 
The definition of post-closure residual risk and how to identify, analyse and manage it through a formal regulatory mechanism varies greatly across mining jurisdictions (Swart \& Erskine 2018). Without clear definition and guidelines for mine practitioners to assess post-closure residual risk, this leads to variation in quality for mine closure design, uncertainty in financial assurance estimates and no clear pathway for the industry relating to post-closure end land use planning and success criteria.

\subsection{Post-closure scenarios to consider residual risk}

The Canadian Dam Association (CDA) provides an overview of post-closure scenarios for managing residual risk in relation to operation, maintenance and surveillance of mining dams. These are described in CDA (2014) and include active care and passive care stages, summarised below. Custodial transfer discussions with regulators and communities of interest can then be established as part of the passive care stage.

\subsubsection{Closure-active care}

Active care can be either during operations (i.e. temporary suspension/care and maintenance) or at the endof-mine life following closure transition/mill decommissioning. For tailings management, during active care, there is ongoing operation, maintenance and surveillance, usually for the purposes of accommodating a water management system. Activities could include surveillance and maintenance of the mining dam and monitoring to verify the performance expected during design. Once pore pressures have stabilised after various closure activities, the dam erosion control measures are effective, and deformations are either nonexistent or are at a steady state and do not present a concern with respect to the stability of the dam, the dam could be considered for closure-passive care stage. A key aspect of the difference between active care and passive care is whether there is a full-time onsite presence for operations of closure infrastructure, monitoring and maintenance.

\subsubsection{Closure-passive care}

Passive care in post-closure considers that mine waste structures that are at a steady state, with self-sustaining processes. A passive care phase is a possible precursor to eventual custodial transfer to government or surrounding communities. The facility is in a steady-state condition and monitoring demonstrates that no further intervention is required by the owner. Some level of inspections by dam safety engineers and dam safety reviews will likely continue with minor maintenance undertaken, as required.

If dam safety failure modes can be designed out to be either non-credible or close to non-credible with the implementation of closure measures, a business case can be established to help refocus LoM planning, permitting and stakeholder engagement. Table 1 summarises typical mine waste structure credible failure modes and suggested closure performance criteria to demonstrate passive care. Chemical stability, end land use and social transition hazards/failure modes are not included but are recommended to be reviewed in context of with potential dam safety failure modes 
Table 1 Potential dam safety criteria to demonstrate passive care

\begin{tabular}{|c|c|}
\hline $\begin{array}{l}\text { Typical failure mode for mine } \\
\text { waste structure (e.g. tailings } \\
\text { facility) })^{1}\end{array}$ & Potential criteria to demonstrate passive care \\
\hline $\begin{array}{l}\text { Overtopping: surface water } \\
\text { from the impoundment } \\
\text { overtops and erodes the } \\
\text { embankment releasing contents }\end{array}$ & $\begin{array}{l}\text { The ultimate tailings facility either cannot form a pond on the surface } \\
\text { (including variations with climate change) and/or has a fixed feature } \\
\text { that is a lower spill point away from the dam. }\end{array}$ \\
\hline $\begin{array}{l}\text { Slope/foundation instability } \\
\text { (static or seismic conditions): } \\
\text { slumping or rapid runout of a } \\
\text { mine waste structure resulting } \\
\text { from slope or foundation failure }\end{array}$ & $\begin{array}{l}\text { Materials in the dam, tailings material and foundation are competent } \\
\text { and dilative. There will not be liquefaction flow or strain weakening } \\
\text { behaviour under static or seismic conditions. Deformations } \\
\text { (settlement or horizontal) have stopped or reached a steady state, } \\
\text { which does not pose concern with respect to stability of the dam. If } \\
\text { there are elements in the dam or foundation that are prone to strain } \\
\text { weakening, then measures have been taken to prevent this. }\end{array}$ \\
\hline $\begin{array}{l}\text { Piping/internal erosion: } \\
\text { enlargement of a continuous } \\
\text { tunnel between upstream and } \\
\text { downstream }\end{array}$ & $\begin{array}{l}\text { There is no requirement for a filter layer to retain base soils and } \\
\text { maintain low seepage forces on the embankment. The pore pressures } \\
\text { in the dam are low under a range of climatic conditions. If there is a } \\
\text { requirement for a filter zone to perform, then it has been } \\
\text { demonstrated that it will work well in the future considering changes } \\
\text { in seepage patterns and behaviour of the filter due to geochemical } \\
\text { effects. }\end{array}$ \\
\hline $\begin{array}{l}\text { Surface erosion: gully erosion } \\
\text { that reduces the factor of safety } \\
\text { of a dam structure (e.g. eroding } \\
\text { a toe buttress). This failure } \\
\text { mode assumes that a pond is } \\
\text { not present at closure, such that } \\
\text { erosion can cause backwards } \\
\text { regression on slopes that can } \\
\text { create a dam overtopping event. }\end{array}$ & $\begin{array}{l}\text { Cover design can withstand a design precipitation event adequate for } \\
\text { the dam safety consequence classification and recognising landform } \\
\text { evolution changes that may occur. If the surface does erode, evidence } \\
\text { is required to show that the cover can 'self-heal' through natural } \\
\text { landform evolution. }\end{array}$ \\
\hline $\begin{array}{l}\text { Geochemical: changes in } \\
\text { material properties leads to } \\
\text { reduced effectiveness of design } \\
\text { controls (e.g. clogging } \\
\text { drainage/filter layers) }\end{array}$ & $\begin{array}{l}\text { Geochemical characterisation and predictions for an agreed } \\
\text { upper-case prediction range does not affect the intended design } \\
\text { function of the mine waste structure. The facility operates passively } \\
\text { without any human or mechanical intervention such as pumping, } \\
\text { water treatment, construction, or frequent maintenance. }\end{array}$ \\
\hline
\end{tabular}

\subsubsection{Custodial transfer}

For a tailings facility to be considered for custodial transfer (some jurisdictions refer to this as institutional control or mine relinquishment), the post-closure scenario requires clear evidence that a dam can be delicensed, and the tailings facility reclassified into a mine waste structure. Criteria summarised in Table 1 is useful to assist in demonstrating a case for passive care and potential reclassification of a tailings facility from a dam to a mine waste structure.

Having a comprehensive knowledge of the triggering events and credible failure modes that may impact achieving custodial transfer, is crucial. Performance evaluation and success criteria can then be properly developed to determine whether proposed closure objectives can be achieved. Physical stability (i.e. geotechnical stability, hydrotechnical/water management, landform erosion aspects) and chemical 
stability (i.e. surface and groundwater quality/quantity, fugitive dust, land contamination, etc.) aspects are crucial. Unless you can demonstrate these are being managed well, a meaningful discussion with stakeholders around a post-mining end land use may not be feasible.

Within Canada, there remains a wide range of variability within mining jurisdictions for establishing clear mechanisms in identifying and transferring mine closure residual risk from the owner to the province/territory. For example:

- Ontario, Canada: discretion for relinquishment is by the director. Ontario. Reg. 240/00: Mine Development and Closure Under Part VII of the Mining Act details the minimum requirements for closure. Section 24 (3) states that 'the proponent shall restore the site to its former use or condition or to an alternate use or condition that the Director sees fit'. (Ontario. Reg. 240/00 2012)

- British Columbia, Canada: discretion for relinquishment is by the chief inspector. Section 10 of the BC Health, Safety and Reclamation Code for Mines in British Columbia (HSRC) details the minimum requirements for closure. Section 10.7.22 states that 'if all conditions of the Act, code and permit have been fulfilled to the satisfaction of the chief inspector and there are no ongoing inspection, monitoring, mitigation or maintenance requirements, the owner, agent or manager will be released from all further obligations under the BC Mines Act'. (Ministry of Energy, Mines, and Petroleum Resources 2017)

- Saskatchewan, Canada: a mechanism for relinquishment is in place. The Reclaimed Industrial Sites Act and Regulations under which the Institutional Control Monitoring and Maintenance Fund and the Institutional Control Unforeseen Events Fund operate. Transfer of title is made to the crown (Government of Saskatchewan 2018).

- Alberta, Canada: a mechanism for relinquishment is in place. Under the Mines and Minerals Act it states that a lessee of an agreement under section 116 may apply to the Minister for a closure certificate in accordance with the regulations (Section 120) and includes assumptions on transfer of liability including indemnification (Section 121). Risk assessment rules for reclamation certificate applications are established via the Specified Enactment Direction 002: Direction for Reclamation Application Submissions for Well Sites and Associated Facilities. Supporting guidelines are provided for a dam de-licensing framework based on a performance and risk-based approach (Oil Sands Tailings Dam Committee 2014).

States and territories across Australia have recently increased scrutiny on rehabilitation securities; however, in all cases, the provision of the security bond does not currently release the company of their obligations. The administering authority decides on the size of the residual risk payment by calculating all potential costs of rehabilitating, restoring and protecting the environment after the resource activity is complete. The Queensland Resource Council's (QRC) has created a position paper on mine closure residual risk (QRC 2019) to help facilitate this discussion with regulators. Additional states across Australia have had recent similar policy revisions.

By comparison, other mining jurisdictions, such as New Zealand, have a clear and transparent mechanism for identifying and transferring residual risk from mining assets. An implemented example from New Zealand is the Martha Mine. Mine closure funds are managed in a trust and interest earned and accumulated to continue to manage long-term risks. A risk assessment supported the development of the closure plan and initial fund and potential contingency amounts that reflect both planned and unplanned risk scenarios (Bowben et al. 2001).

\subsection{Front-end loading with risk assessment}

The best opportunity to make a positive impact on the post-closure residual risk profile is during the early conceptual and planning stages- typically known as the front-end loading (FEL) phase. FEL requirements on capital projects includes robust planning and design early in a project's lifecycle, at a time when the ability to influence changes in design is relatively high and the cost to make those changes is relatively low. 
Some of the key FEL practices for integrated LoM planning are outlined in the 2019 ICMM closure guide. These include establishing a knowledge base, objectives setting, risk and opportunity assessment and developing performance indicators with success criteria (ICMM 2019). There are various opportunities to imbed risk management practices into the tailings and mine waste design FEL closure planning, including:

- Identifying and designing a new tailings or mine waste facility. Risk assessment elements can be incorporated into decision-making evaluation criteria as part of a formal multiple account analysis (MAA) decision support approach.

- Preparing a new closure plan. Risk assessments can provide a platform for engaging on objectives setting, end land use planning, establishing reclamation prescriptions/treatment measures, and setting measurable performance evaluation criteria to meet closure objectives.

- Updating an existing closure plan. Typically required as part of permit conditions this presents an opportunity to engage with a wide range of closure stakeholders.

- Long-term integrated LoM planning. A dam safety risk assessment assessing a current operations risk scenario can inform where the risk profile needs to shift to meet identified land use targets and objectives (e.g. designing out the need to eliminate and reduce the potential for stored water within a tailings impoundment).

If done early as part of FEL engineering practices, the risk management process can be a useful vehicle for change and supporting cost-benefit trade-offs for managing LoM changes (e.g. tailings construction method and technologies, footprint changes, mill process changes, etc.). Conducting a risk assessment highlights attention and resources focused on risks/opportunities that should be prioritised (i.e. non-urgent/important tasks) and reduces silos of communication and planning between mine departments.

\section{$4 \quad$ Tailings designs with a low post-closure physical stability risk}

The authors have a combined experience of 100 years in mine closure and tailings design. Through these experiences, we have summarised a selection of tailings designs that have shown to demonstrate a low postclosure residual risk relating to physical stability.

Backfill of historic open pits and underground voids through a range of tailings technologies and deposition methods provides a robust design for long-term geotechnical closure. There are numerous case studies that have demonstrated this. One example is the Newmont Woodcutters Mine located in the Northern Territory, Australia, where the existing tailings facility was rehandled and backfilled in the open pit at closure. A productive partnership between Newmont and the Woodcutters Liaison Committee is clearing the pathway to handover Woodcutters Mine Site to Traditional Owners, planned for 2020 (Newmont 2014).

Filtered tailings facilities have long-term closure benefits if designed, constructed, and managed well during operations. Advantages of filtered tailings designs at closure include no impoundment of water, improved progressive reclamation, creation of a final landform surface requiring minor recontouring, and the potential for strength gain in the material over time that greatly improves the dynamic performance of the facility. The Hecla-owned Greens Creek Mine, located in Alaska, is an example of filtered tailings design.

Tailings facilities that adopt co-blending of mine rock with filtered tailings also reduce or may eliminate many of the credible failure modes associated with dam stability. In addition, there are added environmental benefits of co-blending including lower water use during operations, a smaller overall mine waste footprint and improved measures to prevent the onsite of metal leaching and acid rock drainage (ML/ARD). An example of co-blending geo-waste is the Newmont Goldcorp and FLSmidth EcoTails ${ }^{\mathrm{TM}}$ filter technology that is being considered for full-scale testing at the Peñasquito mine, located in Mexico.

The Hidden Valley mine is a gold/silver mine in Papua New Guinea with the first large engineered tailings facility since large-scale mining began in the country over 80 years ago. The TSF is comprised of two large earth and rockfill dams, raised by the downstream method. The dams are constructed of pit waste and therefore have the dual function of storing tailings and waste rock (Rynhoud et al. 2017). When designed correctly, the downstream dam method has a greater level of robustness to withstand maximum credible 
earthquake (MCE) events that may not be experienced until many hundreds (or thousands) of years during a post-closure state.

The Brenda Mine tailings facility, located in British Columbia, Canada, designed by Klohn Crippen Consultants and constructed between 1969 and 1986, the main dam is classified under CDA as an 'extreme' consequence facility. The main dam is $137 \mathrm{~m}$ high, $2 \mathrm{~km}$ long dam used a centreline construction, conventional cycloned sand tailings technology approach. Elements that support a large dam with low residual risk during closure include a long beach length (>800 $\mathrm{m}$ from the dam crest) and spillway designed to pass the probable maximum flood (PMF), designed for the MCE, includes a downstream dam shell comprised of cycloned sand that allows for lower phreatic and pore pressure conditions, is not susceptible to internal erosion, and has a downstream slope cover that has minimum erosion requiring maintenance (Lo et al. 2009; MBS Geoconsulting 2016).

Hence, even though the dam is classified as extreme under CDA, the structure can be considered a low risk dam because of the measures that were taken during design and construction with an eye on closure. The site is in active care closure currently as water treatment is ongoing for molybdenum. But, after water treatment is completed and water can be directly discharged from the pond to the environment, this site could be considered eligible for moving into passive care closure because of the performance of the containment dams.

\section{Conclusion}

Key conclusions from this paper include:

- It is important that closure risk assessments that are done during the LoM are comprehensive, effective, and able to be updated over the life of the mine. Through the risk assessment process, aim to reduce the number and severity of credible tailings failure modes early in the LoM through engineering design and integrated life-of-mine planning.

- Having a comprehensive technical basis of the triggering events and credible failure modes for tailings and mine waste structures is crucial to assist in selecting closure goals and success criterial.

- Closure scenarios being assessed should be well defined in establishing the risk assessment scope, context and criteria. Prior to closure risk assessments, effort should be made to bring closure design to a pre-feasibly level to improve decision-making outcomes.

- An alternative approach to defining risk likelihood presented by the authors has proven to be useful in better communicating the risks and supporting identification of critical controls for long-term failure modes initiated from natural events, such as earthquake or flood.

- Many of the tailings failures are a culmination of smaller but related events that typically has a human element at the centre. Human factors including normalisation of deviance should be accounted for in the risk assessment process through governance assurance measures.

- Risk communication is an opportunity for improvement. The results and nature of credible failure mode(s) assumed must be explainable to the least technical person that will be in a target audience. There remain challenges in objectively quantifying the likelihood and consequence of credible failure modes for external stakeholders in determining what is socially acceptable residual risk. A case-by-case approach with early engagement is recommended to define risk terms and identify the range of tolerable and intolerable post-closure risk.

\section{Acknowledgement}

The authors of this paper acknowledge the industry representatives who provided their time in contributing ideas and discussion to this important topic. 


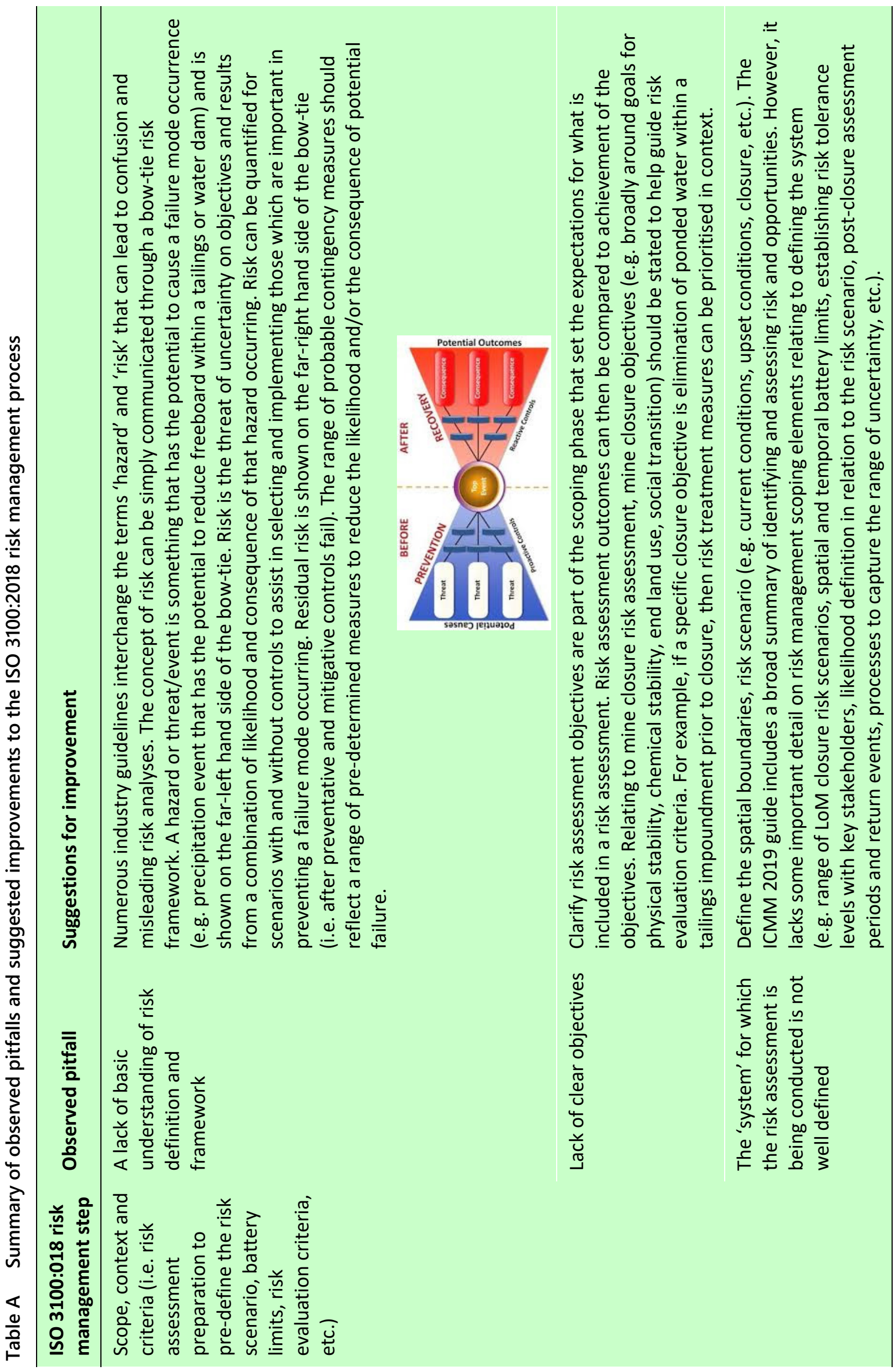




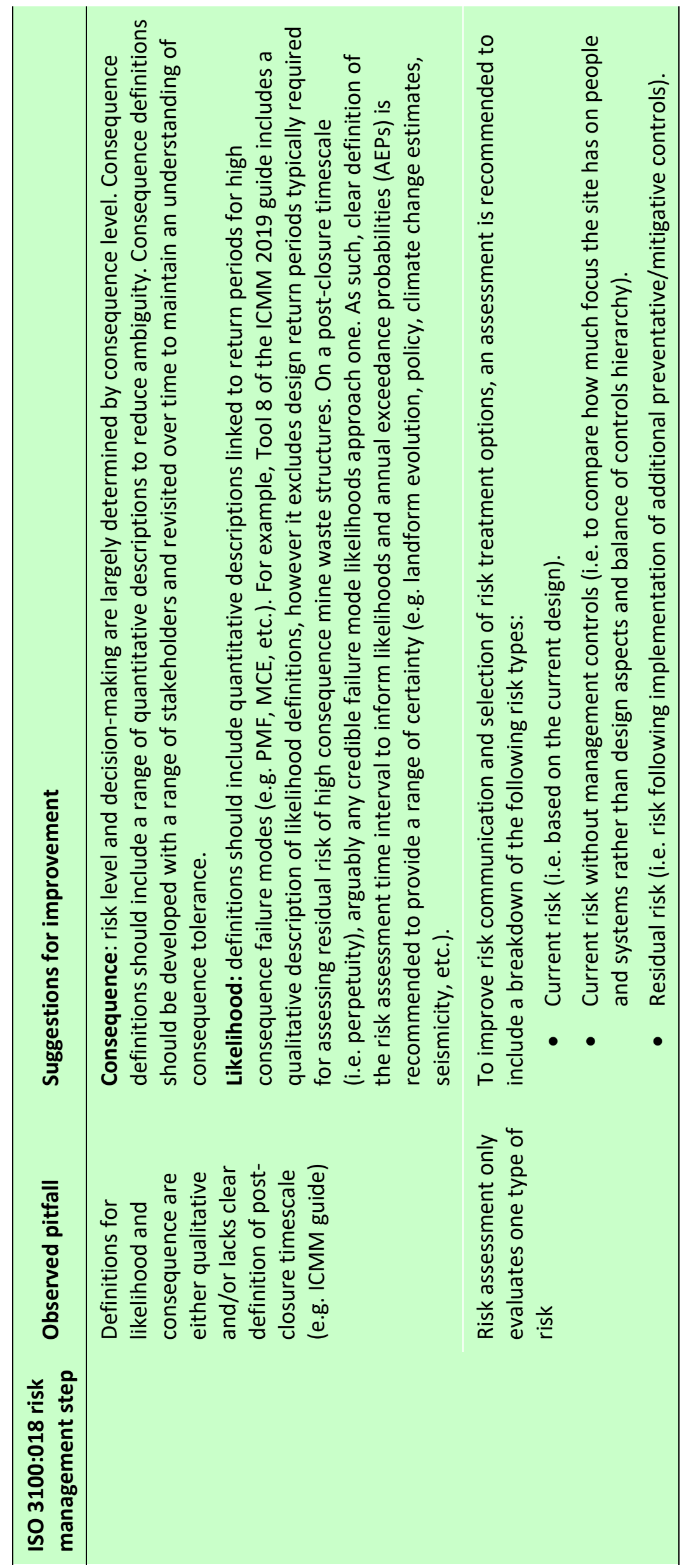




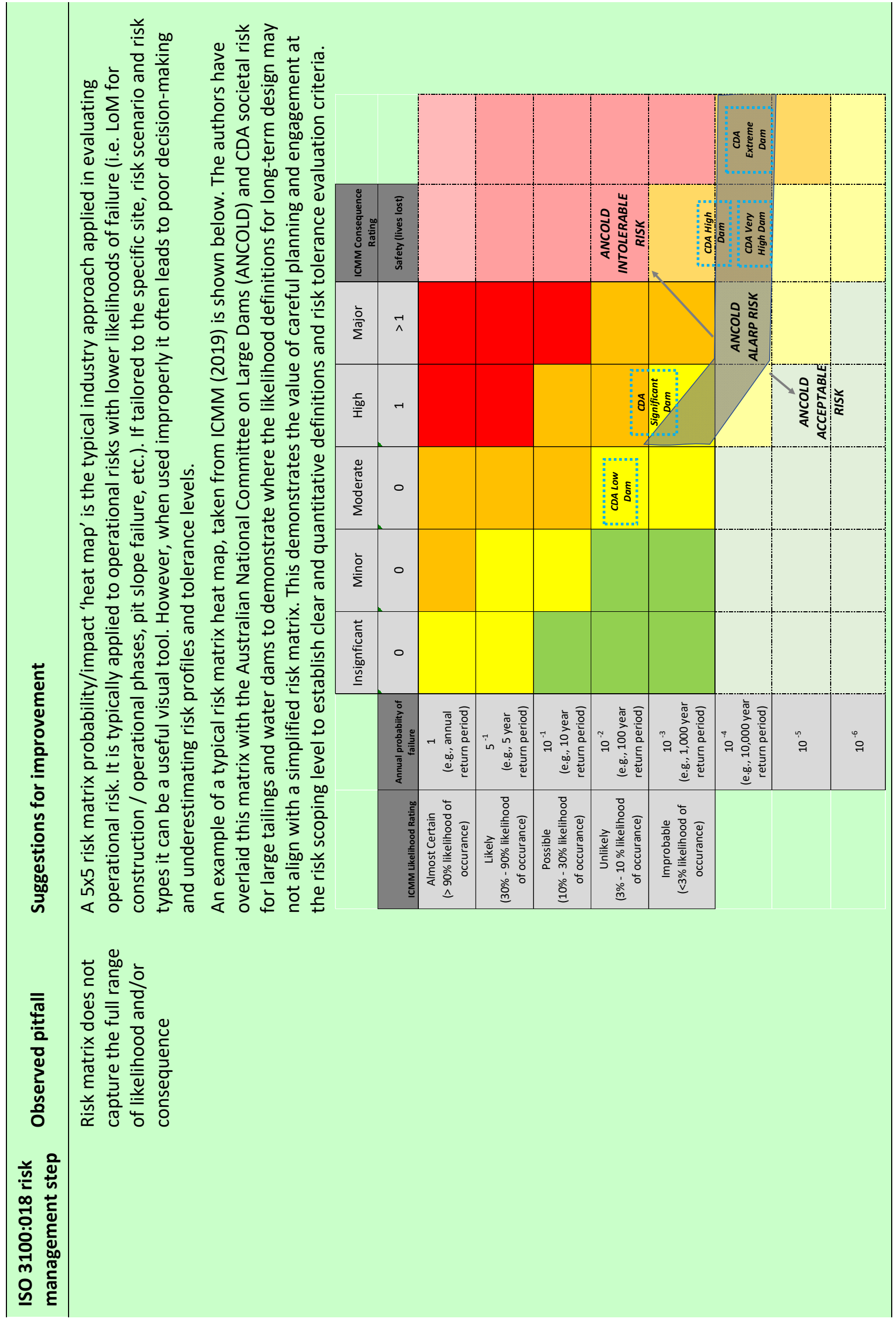




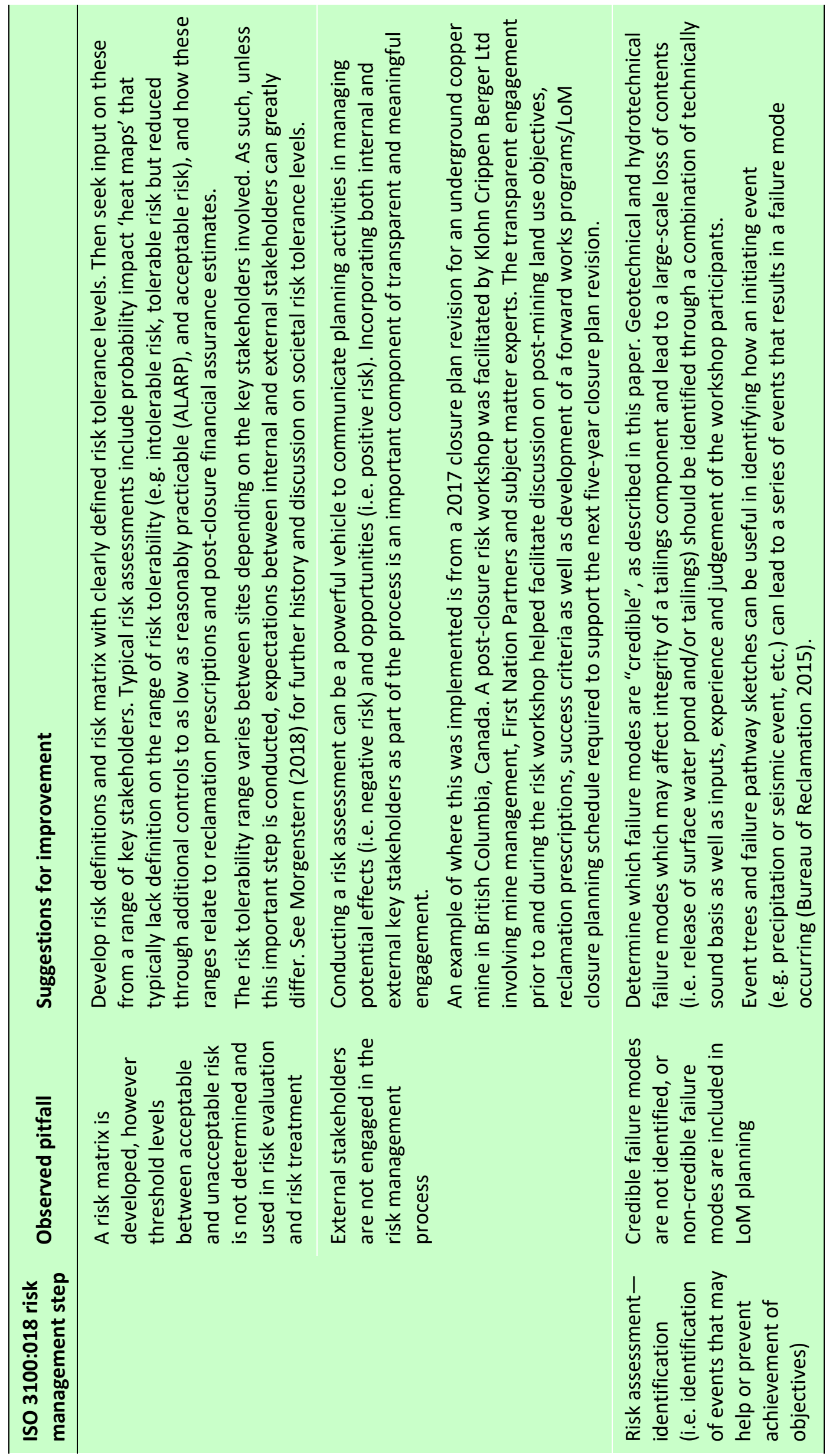




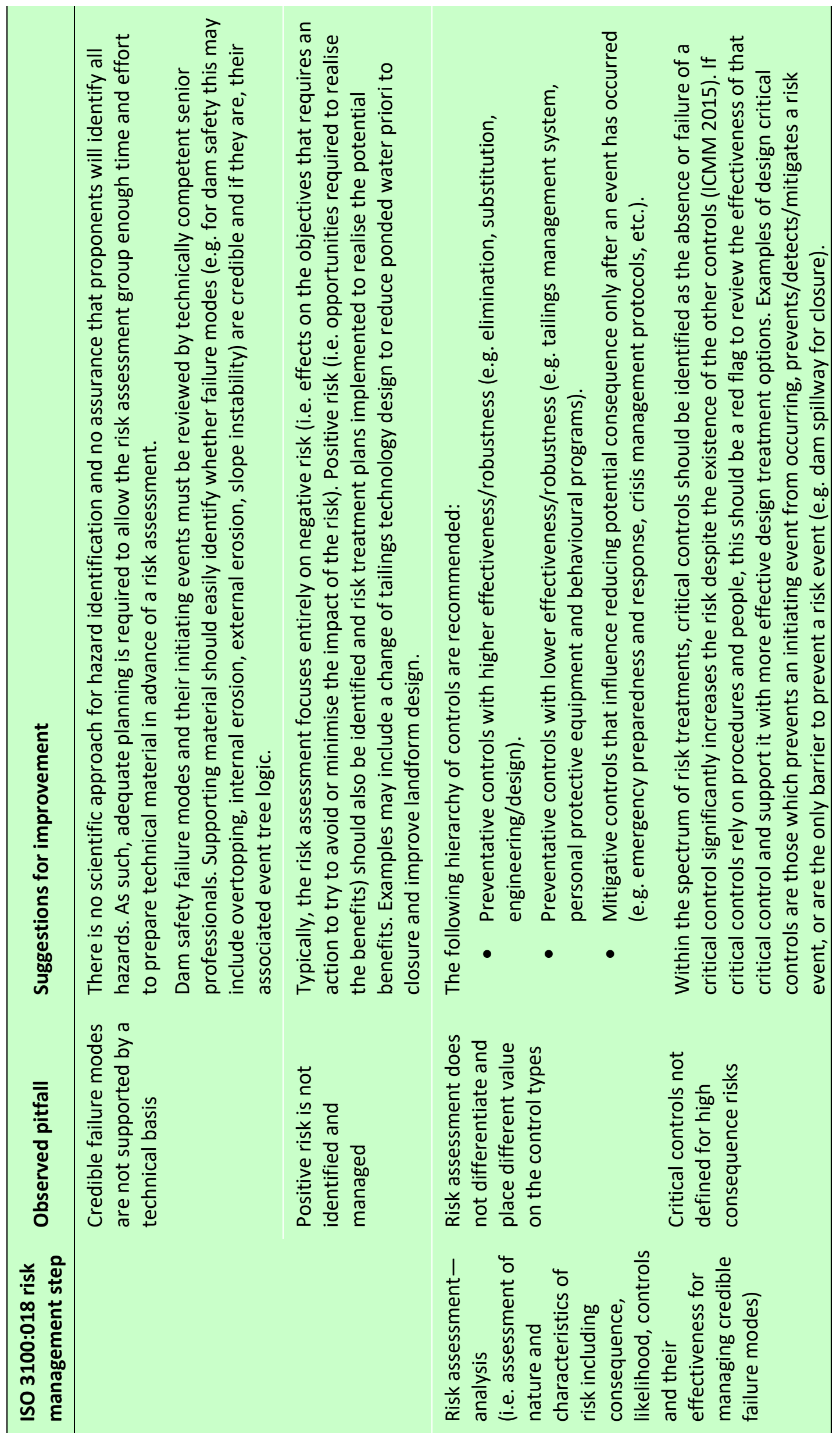









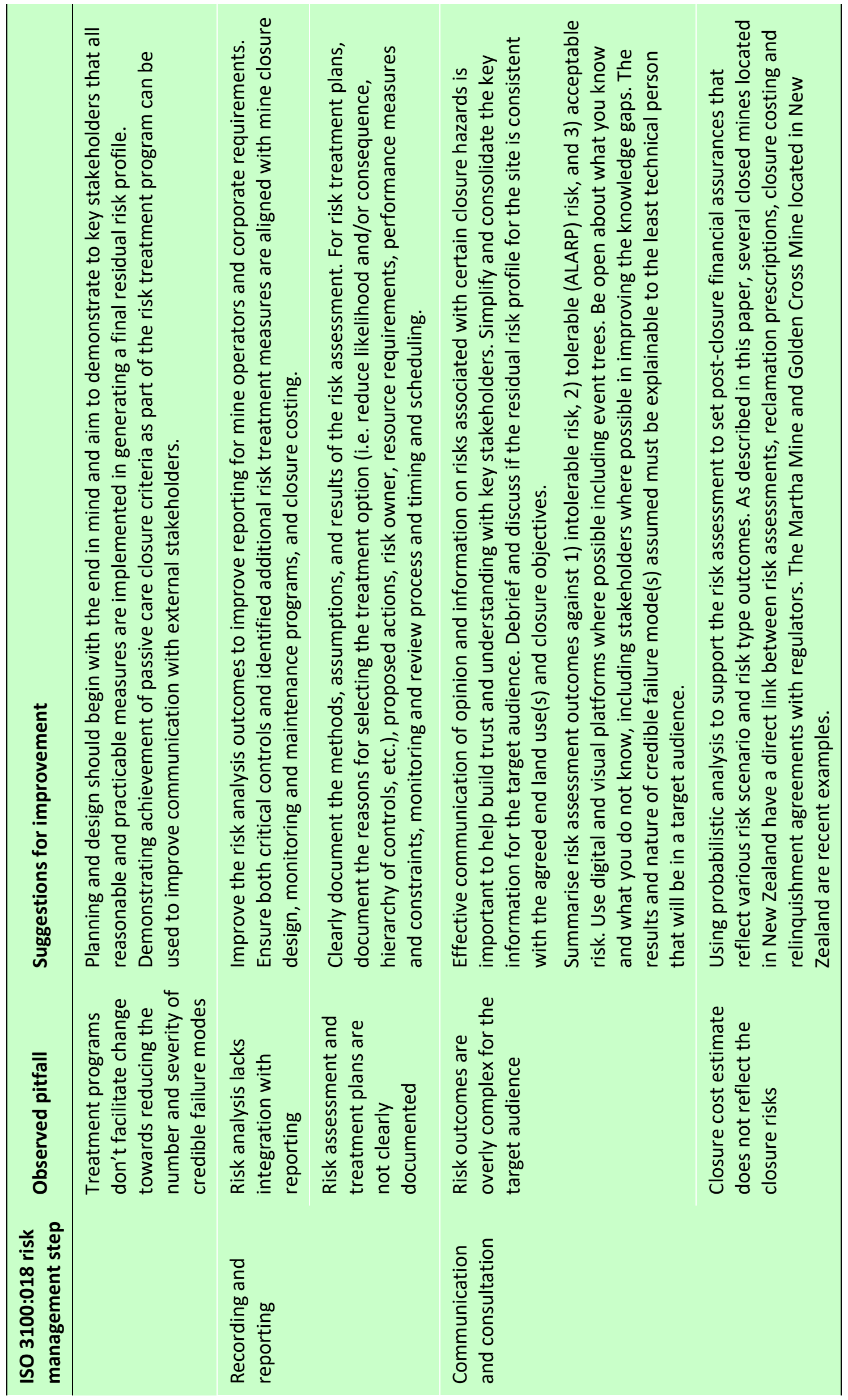




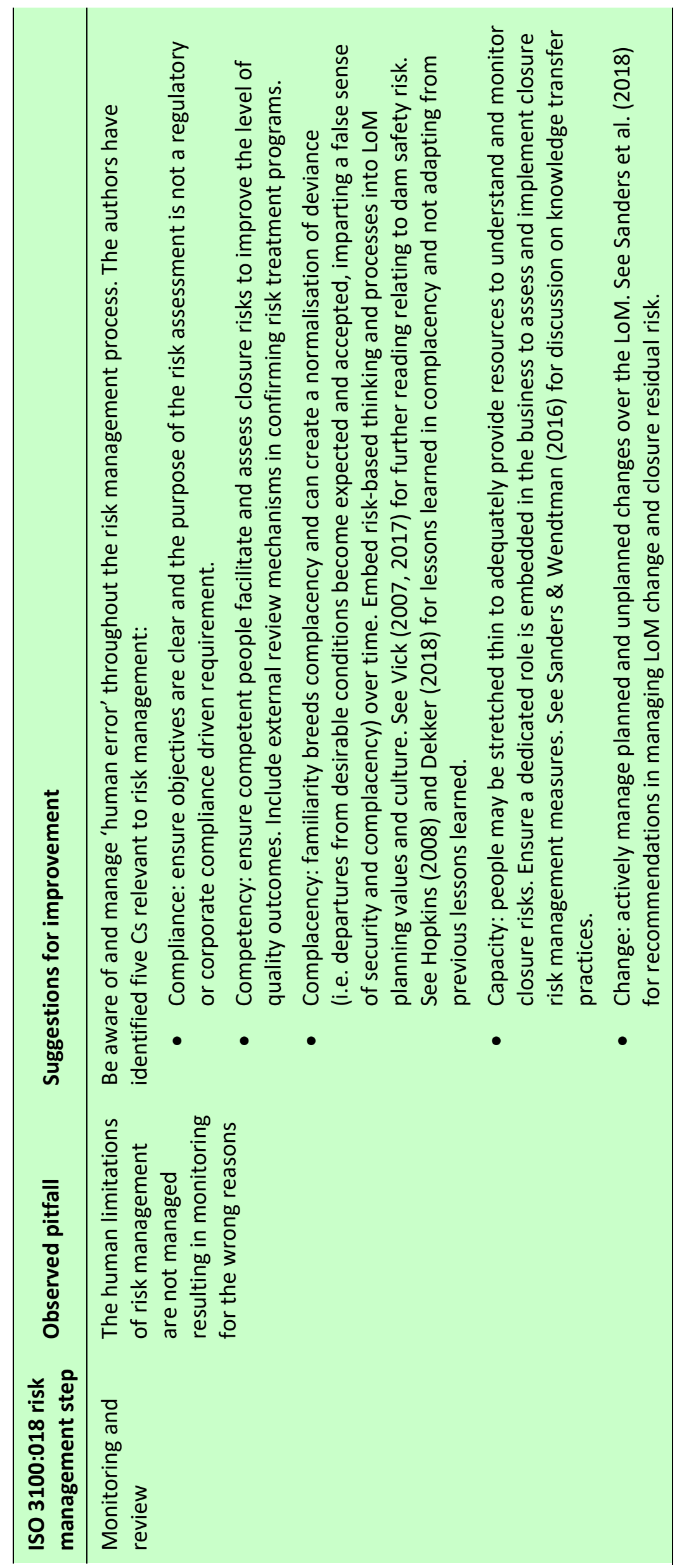




\section{References}

Ministry of Energy, Mines, and Petroleum Resources 2017, Health, Safety and Reclamation Code for Mines in British Columbia, Crown Publications, Victoria.

Bowben, AR, Lane, MR \& Martin, JH 2001, Triple Bottom Line Risk Management - Enhancing Profit, Environmental Performance and Community Benefits, Wiley.

Canadian Dam Association 2014, Application of Dam Safety Guidelines to Mining Dams, Toronto.

Ernst and Young 2019, Business Risks Facing Mining and Metals: 2019 - 2020, London.

Dekker, S 2018, Drift into Failure, Routledge, Abingdon.

Government of Saskatchewan 2018, Institutional Control Monitoring and Maintenance Fund and the Unforeseen Events Fund Annual Report 2017-18, Ministry of Economy, Regina.

Hopkins, A 2008, Failure to Learn: the BP Texas City Refinery Disaster, CCH Australia, Sydney.

International Council on Mining and Metals 2019, Integrated Mine Closure Good Practice Guide, London.

International Council on Mining and Metals 2015, Health and Safety Critical Control Management, London.

International Organization for Standardization 2018, Risk Management - Guidelines (31000:2018), Geneva.

Lo, RC, Stroiazzo, J \& Guilleminot, G 2009, 'Transition of a major tailings facility in a sensitive environment - from operation to decommissioning at Brenda Mine', in AB Fourie \& M Tibbett (eds), Proceedings of the Fourth International Conference on Mine Closure, Australian Centre for Geomechanics, Perth, pp. 229-243.

MBS Geoconsulting 2016, 2016 DSI report for the Brenda Mine Site, viewed 10 May 102019 , https://mines.empr.gov.bc.ca/p/brenda/docs

Morgenstern, N 2018, 'The 6th Victor de Mello Lecture: geotechnical risk, regulation and public policy', paper presented at the 9th Portugse-Brazillian Geotechnical Congress, Salvador, 30 August 2018.

Newmont 2014, News Release: Indigenous Consulting Group to Help Clear Pathway to Hand Over Woodcutters, viewed 24 July 2019 , https://investors.newmontgoldcorp.com/news-release/news-details/2014/Indigenous-Consulting-Group-to-help-clearpathway-to-hand-over-Woodcutters/default.aspx

Oil Sands Tailings Dam Committee 2014, De-licensing of Oil Sands Tailings Dams. Technical Guidance Document, https://doi.org/10.7939/R3QJ7811S

Queensland Resource Council 2019, Managing Residual Risk in Queensland, Queensland Government.

Rynhoud, MS, Johns, D \& Murray, L 2017, 'The Hamata Tailings Dam design and construction at the Hidden Valley Mine in Papua New Guinea', presented at the ANCOLD 2017 Conference, Hobart, 26-27 October 2017.

Sanders, J Wendtman, M \& Sexton, A 2018, 'Change management over the life of mine: challenges and opportunities for closure residual risks', in C Drebenstedt, F von Bismarck, AB Fourie \& M Tibbett (eds), Proceedings of the 12th International Conference on Mine Closure, Technical University Bergakademie Freiberg, Freiberg, pp. 315-329.

Sanders, J \& Wendtman, M 2016, 'Managing knowledge loss over the life of mine: opportunities and challenges', Proceedings of Risk and Resilience Mining Solutions 2016, InfoMine Inc., Vancouver.

Swart, P \& Erskine, PD 2018, 'Residual risk policy and processes - what is holding the industry back from achieving mine closure ad lease relinquishment', in C Drebenstedt, F von Bismarck, AB Fourie \& M Tibbett (eds), Proceedings of the 12th International Conference on Mine Closure, Technical University Bergakademie Freiberg, Freiberg, pp. 189-197.

Bureau of Reclamation 2015, Best Practice in Dam and Levee Safety Risk Analysis, viewed September 2018, https://www.usbr.gov/ssle/damsafety/risk/methodology.html

Vick, S 2007, 'Dams, levees, and risk - the good, the bad, and the ugly', Proceedings of 26th Annual Water Management Conference, American Society of Civil Engineers, Reston.

Vick, S 2017, 'From deviance to diligence', in J Huang, GA Fenton, L Zhang \& DV Griffiths (eds), Proceedings of Geo-Risk 2017, American Society of Civil Engineers, Reston. 
